\title{
ESTRUTURA DE MERCADO E ESTRATÉGIA: UM ESTUDO NA INDÚSTRIA BRASILEIRA DE BATERIAS AUTOMOTIVAS
}

\section{RESUMO}

Dadas as configurações da indústria e os grupos estratégicos, diferentes estratégias são requeridas por parte das empresas para responder à estrutura de mercado. Especialmente ao se considerar oligopólios competitivos, muitos estudos focam nas grandes empresas do núcleo desses setores. Entende-se que a compreensão das estratégias das firmas que atuam às margens das grandes oligopolistas, ou seja, na "franja" desses mercados, também é relevante, pois a escolha estratégica e o desempenho das empresas na "franja" interferem na dinâmica de todo o setor. Com base no paradigma Estrutura-Conduta-Desempenho da Organização Industrial, o presente trabalho tem por objetivo revelar como as estratégias das firmas na "franja" se alinham à estrutura de mercado de baterias automotivas para reposição. Para tanto, foi realizada pesquisa qualitativa descritiva, por meio de entrevistas semiestruturadas com diretores de quatro firmas fabricantes de baterias para reposição. Os resultados apontam que a concorrência em preço, típica de firmas na franja, é suportada não só por práticas de políticas de preço e redução de custos, mas também pela combinação de outras condutas, tais como de inovação e qualidade. A elevada heterogeneidade, característica de oligopólios competitivos, é observada dentro da própria "franja", envolvendo empresas com diferentes padrões técnicos, tecnológicos e de escala, inclusive no mercado informal. Assim, observa-se grande complexidade competitiva nesse setor, indicando que políticas voltadas para empresas da franja devem considerar o fomento a condutas de não preço e a eliminação de falhas de mercado decorrentes da concorrência desleal praticada por firmas que atuam na informalidade.

Palavras-chave: Oligopólio competitivo; Mercado de Baterias de Reposição; Indústria de Baterias.

\section{MARKET STRUCTURE AND STRATEGY: A STUDY IN THE INDUSTRY OF AUTOMOTIVE BATERIES}

\section{ABSTRACT}

To face market structure, companies in different strategic groups need to design different strategies. Especially concerning competitive oligopolies, many studies focus on large companies in the core of sectors. We consider that the analysis of strategies of companies in the margin of large companies, i.e. in the "fringe" of those markets, are also relevant, since strategic choice and performance of firms in the "fringe" influences sectorial dynamics. Based on Industrial Organization and Structure-Conduct-Performance paradigm, this papers aims to analyze how strategies of companies in the "fringe" are aligned to the market structure of non-OEM automotive battery. This qualitative descriptive research comprised semi structured interviews with managers of four non-OEM battery manufacturers. Results revealed the importance of market structure for firms' conduct: the need to compete on price make firms to combine different strategies. Besides price strategies to support price competition, typical for companies in the "fringe" of competitive oligopolies, firms set a combination of different strategies, such as innovation and quality, which indicates complexity in terms of strategies. Thus, price competition is largely supported by non-price strategies. Firms' diversity, a remarkable feature in competitive oligopolies, is also observed in the "fringe", which includes differences in terms of techniques, technologies and scale, and the existence of informal market. Thus, high competition complexity indicates the need of public policies to foment non-price strategies even for firms in the "fringe" and to reduce market failures from informal firms' competition.

Keywords: Competitive Oligopoly; Non-OEM Automotive Battery Market; Automotive Battery Industry. 


\section{ESTRUCTURA DEL MERCADO Y ESTRATEGIA: UN ESTUDIO EN LA INDUSTRIA BRASILEÑA BATERÍAS DE AUTOMOCIÓN}

\section{RESUMEN}

Teniendo en cuenta la configuración de la industria y los grupos estratégicos, diferentes estrategias son requeridos por las empresas para responder a la estructura del mercado. Especialmente cuando se considera oligopolios competitivos, muchos estudios se centran en las grandes empresas en el núcleo de estos sectores. Se entiende que la comprensión de las estrategias de las empresas que operan al margen de la gran oligopolio, es decir, la "franja" de estos mercados, también es relevante porque la elección estratégica y el desempeño de las empresas en la "franja" interfieren con la dinámica de la totalidad el sector. Sobre la base de la Organización Industrial paradigma estructura-conductadesempeño, este trabajo pretende mostrar cómo las estrategias de las empresas de la "franja" se alinean con la estructura del mercado de baterías de automóviles para su sustitución. Por lo tanto, se realizó una investigación cualitativa descriptiva, a través de entrevistas semiestructuradas con los directores de las cuatro firmas de reemplazo fabricante de la batería. Los resultados muestran que la competencia en los precios, las empresas típicas en la periferia, es apoyada no sólo por las políticas de precios y prácticas de reducción de costes, sino también por la combinación de otros enfoques, como la innovación y la calidad. La alta heterogeneidad, característica de los oligopolios de la competencia, se observa dentro de la "franja" que participan empresas con diferentes normas técnicas, la tecnología y la escala, entre ellos en el mercado informal. Por lo tanto, existe una gran complejidad competitiva en este sector, lo que indica que las políticas destinadas empresas marginales deben considerar el fomento de la realización de valor incalculable y la eliminación de los fallos del mercado que surgen de la competencia desleal de las empresas que operan de manera informal.

Palabras clave: Oligopolio Competitivo; Las Baterías de Reemplazo de Mercado; Industria de las Baterías.

1 Doutoranda em Administração da Universidade Estadual de Maringá - UEM. Brasil. E-mail: profjaiane@yahoo.com.br

${ }^{2}$ Doutora em Engenharia de Produção pela Universidade Federal de São Carlos - UFSCar. Professora da Universidade Estadual de Maringá - UEM. Brasil. E-mail: smsbankuti@uem.br 


\section{INTRODUÇÃO}

Diferentes estratégias são requeridas por parte das empresas para responder a estrutura de mercado nas diferentes indústrias. A estrutura de mercado refere-se a vários componentes que determinam o mark-up das firmas, envolvendo o número e o tamanho das firmas, os tipos de produtos desenvolvidos, a possibilidade de economias de escala, as barreiras de entrada, entre outros (Lipczynski \& Wilson, 2004). Entender as características de determinada indústria e consequentemente seu ambiente competitivo se torna essencial para o desenvolvimento de estratégias.

Tais preocupações na teoria da Estratégia se originam da Organização Industrial (Lipczynski, Wilson, \& Goddard, 2009). Dentre as diferentes perspectivas de análise de funcionamento dos mercados e comportamento das firmas, destaca-se o paradigma Estrutura-Conduta-Desempenho (ECD), o qual contribui para uma análise da estrutura de mercado da indústria, bem como as condições de conduta e o desempenho da firma. O modelo ECD busca, a partir de características da estrutura do mercado, explicar o desempenho em termos de alguma variável escolhida, supondo para isso que a conduta das empresas está fortemente condicionada aos parâmetros estruturais vigentes (Scherer \& Ross, 1990; Fagundes \& Pondé, 1998).

A indústria de baterias automotivas possui uma estrutura de mercado bastante particular. Ela sobreviveu ao processo de abertura comercial dos anos de 1990, havendo acentuada presença de empresas de capital nacional, que respondem por cerca de $75 \%$ do mercado brasileiro total. O Brasil possui amplo parque industrial, sendo que os estados de São Paulo e do Paraná concentram a maior parte dessa atividade (Castro, Barros, \& Veiga, 2013).

Observa-se, nessa indústria, dois mercados distintos: aquele associado a vendas para as montadoras de veículos, também denominada Original Equipment Manufacturer [OEM]; e o mercado de reposição, para substituição de baterias em veículos usados. As vendas para as montadoras são concentradas na empresa brasileira Moura e na norteamericana Johnson Controls, cada uma tem cerca de metade do mercado de OEM, embora outras empresas eventualmente forneçam para montadoras de menor porte instaladas no Brasil. No mercado de reposição, há maior pulverização, com notável presença de empresas de menor porte e de capital nacional. Nesse mercado de reposição, a empresa Moura é líder de mercado e possui um market share de cerca de $30 \%$, contra aproximadamente $25 \%$ da Johnson Controls, sendo que os $45 \%$ restantes estão divididos entre diversas fabricantes (Castro, Barros, \& Veiga, 2013). ${ }^{3}$

\footnotetext{
${ }^{3}$ Vale destacar que nesse mercado existe a participação do mercado informal, porém não há mensuração nem estimativas dessa atividade. São empresas clandestinas que
}

Devido a essas características tão marcantes dessa indústria, as firmas precisam estar atentas ao desenvolvimento de estratégias para alcançar um desempenho adequado. Neste artigo, entende-se que o desempenho depende da adoção de estratégias apropriadas, alinhadas às características da estrutura de mercado no qual as empresas estão inseridas. Portanto, a seguinte pergunta de pesquisa direcionou o artigo: como as estratégias utilizadas por empresas na "franja" do oligopólio competitivo estão alinhadas à estrutura de mercado de baterias automotivas para reposição? Ademais, a influência da conduta no desempenho e na estrutura de mercado pode indicar novas dinâmicas na indústria, sendo essencial a compreensão da interação entre os elementos da estrutura, conduta e desempenho.

A maior parte da literatura realiza estudos sobre o desempenho das firmas (Goddard, Tavakoli, \& Wilson, 2005; Anh, Binh, \& Duong, 2014; Short, McKenny, Ketchen, Snow, \& Hult, 2015). Estudos sobre a estratégia em mercados oligopolizados são frequentemente realizados com foco nas grandes firmas dominantes nesses mercados, como no caso da indústria automobilística (Silva, 2001), da telefonia (Teixeira, Lacerda, Hexsel, \& Castagno Junior, 2005), papel e celulose (Costa \& Garcias, 2009), alimentos e bebidas (Setiawan, Emvalomatis \& Lansink, 2013) e petróleo (Demel, 2014). Entretanto, o foco é na estrutura de mercado ou no desempenho, havendo carência de discussões acerca da conduta.

Apesar da representatividade das grandes fabricantes de baterias, é importante compreender o ambiente competitivo e as estratégias das empresas de menor porte nesse mercado. A configuração de mercados de oligopólio competitivo, com poucas grandes empresas no núcleo e muitas empresas menores na "franja" (Possas, 1987; Farina, 1999) implica diversidade de grupos estratégicos e consequentemente de estratégias competitivas. Estudos sobre franja competitiva apenas sinalizam sua existência e discutem a importância da manutenção da franja para fins competitivos (Chen, 2003; Farina, Nunes, \& Monteiro, 2005; Neves \& Conejero, 2010; Beiral, Moraes \& Bacchi, 2013), porém não avançaram nas estratégias utilizadas pelas firmas. Portanto, considera-se importante a compreensão das estratégias das empresas na margem de oligopólios competitivos, dado que as decisões estratégicas e o desempenho dessas empresas interferem no funcionamento e na dinâmica da indústria como um todo.

fabricam as baterias chumbo-ácido sem cumprir nenhuma norma ou regulamentação, o que ocasiona num preço menor que o de mercado. Contudo, esses produtos apresentam características inferiores, durabilidade menor e ainda podem ser nocivos à saúde, já que não seguem a legislação e não cumprem requisitos básicos de segurança. Há ainda o recondicionamento de baterias feito por auto elétricas, sendo que algumas podem fazer esse trabalho em uma maior escala. 
Diante do exposto, o objetivo desta pesquisa é objetivo revelar como as estratégias das firmas na "franja" se alinham à estrutura de mercado de baterias automotivas para reposição. De forma específica, o artigo busca caracterizar os componentes da estrutura de mercado de baterias automotivas, descrever as estratégias utilizadas pelas empresas e discutir sobre as estratégias utilizadas pelas firmas frente à estrutura de mercado dessa indústria.

Considerando a concentração de fabricantes existentes no norte do Paraná, optou-se por estudar quatro empresas localizadas nessa região. Essas firmas competem pelos $45 \%$ restantes do mercado de reposição, por isso, tentou-se evidenciar suas estratégias na busca por uma posição.

Este artigo está estruturado da seguinte maneira: além desta introdução, na seção seguinte apresenta-se o referencial teórico envolvendo a organização industrial e o paradigma ECD, bem como as estratégias das firmas e o oligopólio competitivo. Depois, discorre-se sobre os procedimentos metodológicos adotados nesta pesquisa. Os resultados são apresentados e discutidos em seguida. Por fim, são apresentadas as conclusões do trablho.

\section{ORGANIZAÇÃO INDUSTRIAL E O PARADIGMA ESTRUTURA - CONDUTA - DESEMPENHO}

A preocupação central da Organização Industrial (OI) está no funcionamento dos mercados e das indústrias, principalmente na forma em que as empresas concorrem entre si. Especificamente, em sua concepção, a OI preocupa-se em explicar o funcionamento dos mercados em concorrência imperfeita (Cabral, 2000). Schmalensee (1988), ao discorrer sobre o escopo da Organização Industrial, destaca que este envolve dois focos específicos: o primeiro deles, mais preocupado com o comportamento, escala, escopo e organização das firmas; o outro, direcionado para a concorrência imperfeita.

Dentre as diversas perspectivas de estudo na Organização Industrial, destaca-se o paradigma Estrutura-Conduta-Desempenho (ECD) (Scherer \& Ross, 1990; Lipczynski, Wilson, \& Goddard, 2009; Hasenclever \& Kupfer, 2013). Seu objetivo é fornecer uma caracterização, recorrendo a um esquema que relaciona a estrutura de mercado com o comportamento dos agentes econômicos que operam nele e com o desempenho gerado por esses agentes. Dentro desse esquema, examina-se: (1) o número de concorrentes que atuam no mercado e a distribuição de market share; (2) as condições de entrada e de saída; (3) a padronização do produto e a proximidade de produtos substitutos; (4) a interdependência entre as atividades a montante e a jusante; e (4) a qualidade das informações controladas por parceiros e do grau de risco envolvido (Jacquemin, 2000).

O marco das discussões da OI é o modelo de análise de mercado conhecido como ECD, desenvolvido por Mason (1939) e formalizado por Bain (1959) (Saes, 2009). A partir desse modelo discute-se que a estrutura de mercado afeta as estratégias e consequentemente o desempenho das firmas (Lipczynski \& Wilson, 2004). A figura 1 apresenta um esquema do paradigma ECD. 


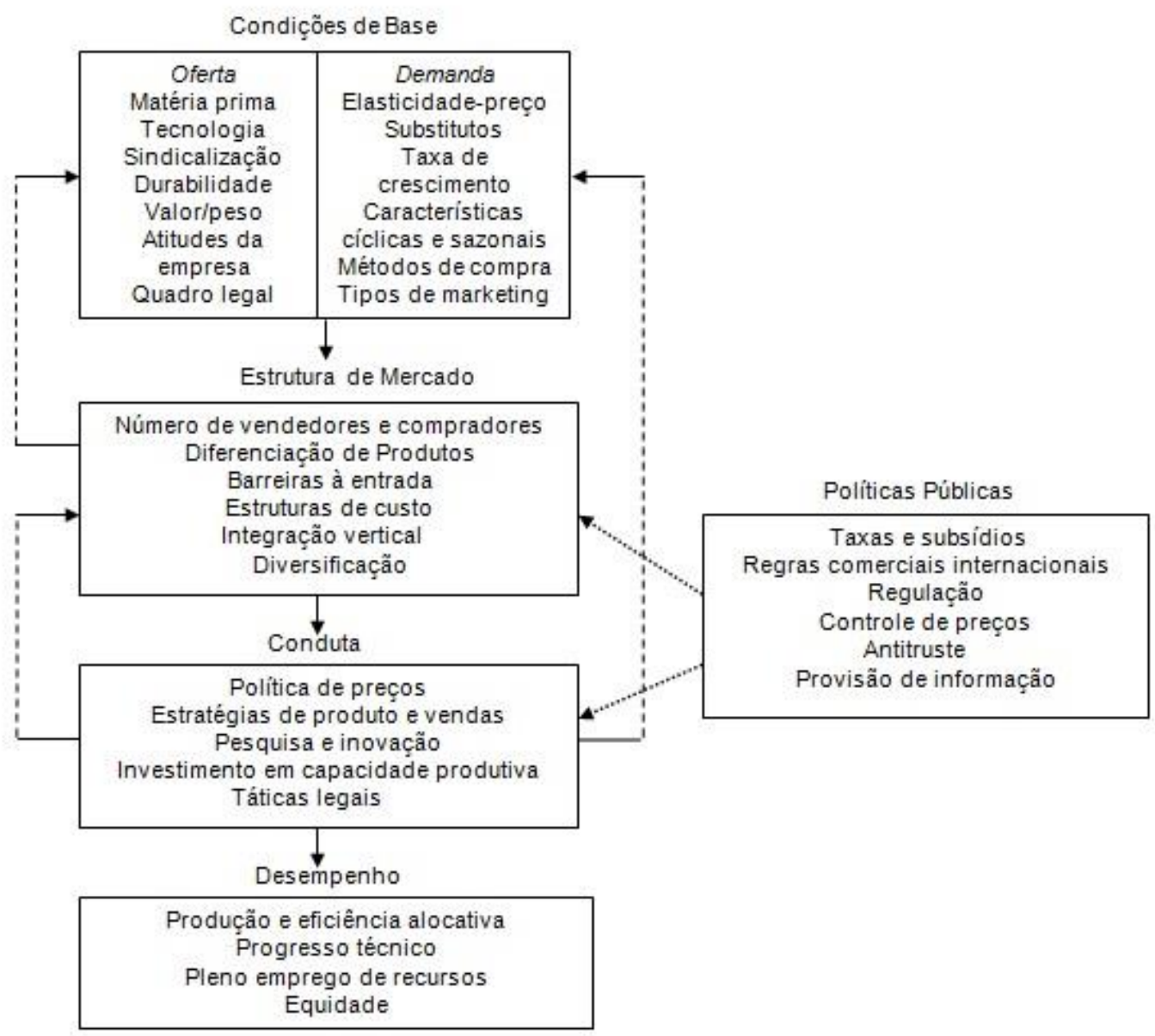

Figura 1 - Paradigma Estrutura-Conduta-Desempenho Fonte: Scherer and Ross (1990, p. 5).

Observa-se que a estrutura de mercado determina a conduta, e esta, o desempenho da firma. Os determinantes da estrutura, por sua vez são as condições de base da oferta e a da demanda. As condições de oferta podem incluir a localização de matéria prima, a natureza da tecnologia relevante, o grau de sindicalização da força de trabalho, a durabilidade dos produtos, o padrão de tempo de produção, a relação valor/peso do produto, atitudes da empresa e o quadro legal. As condições da demanda devem incluir a elasticidade-preço da demanda, a disponibilidade de produtos substitutos, a taxa de crescimento e variabilidade da demanda ao longo do tempo, os métodos utilizados pelos compradores e as características de comercialização do produto (Scherer \& Ross, 1990).

A estrutura é apresentada pelo número de produtores e compradores, a diferenciação de produtos, as barreiras à entrada, estruturas de custo, integração vertical e diversificação. As características estruturais geralmente mudam lentamente, podendo ser consideradas fixas ao longo do tempo (Lipczynski \& Wilson, 2004). De forma geral, as estruturas de mercado são: (1) concorrência perfeita, com grande número de vendedores para um produto personalizado, sem barreiras à entrada; (2) concorrência monopolística, com grande número de vendedores, porém com alguma diferenciação que permite a formação de "monopólio"; (3) oligopólio, com um número limitado de empresas; (4) monopólio, com uma única empresa operando; e (5) duopólio, com duas firmas operando (Hasenclever \& Kupfer, 2013).

Com relação aos mercados tipicamente competitivos, as principais estruturas de mercado são: (1) mercado competitivo, não-oligopolístico, quando ele é fragmentado, com produto homogêneo ou com baixa diferenciação e com ausência de barreiras à entrada; (2) oligopólio concentrado, de elevada concentração, com produto homogêneo ou de baixa diferenciação e elevadas barreiras técnicas; (3) oligopólio diferenciado, de elevada concentração e com produto diferenciado e barreiras de diferenciação, reforçando barreiras técnicas; (4) oligopólio diferenciado-concentrado ou misto, combinando elementos do oligopólio diferenciado e do concentrado, resultando na diferenciação de produtos como forma de competição por excelência; e (5) oligopólio competitivo, de alta concentração, com possibilidade 
de competição em preços em virtude da existência de empresas "marginais"; ou seja, há presença de uma franja competitiva, produtos diferenciados e barreiras de diferenciação (Possas, 1987 ; Farina, 1999).

Com relação à conduta, apesar de não existir um consenso entre os autores em termos de uma tipologia, algum padrão é observado. Consideram-se dois tipos distintos de conduta: conduta competitivas, que acirram a concorrência entre as firmas, e condutas anticompetitivas, de conluio, por meio de acordos tácitos ou explícitos, envolvendo acordos sobre preço, quantidade, regiões de atuação, qualidade, entre outros. Dentro das práticas competitivas, observam-se concorrência em preço, em que a disputa entre as firmas acontece pela guerra de preços, e concorrência não preço, envolvendo práticas como diferenciação, inovação, publicidade e propaganda, diversificação e integração vertical (Lipczynski, Wilson, \& Goddard, 2009).

Para Scherer and Ross (1990), as condutas são identificadas por meio da política de preços, estratégias de produto e vendas, pesquisa e inovação, investimento em capacidade produtiva e táticas legais. As condutas são diferenciadas e motivadas principalmente pelo tipo de estrutura da indústria (Hasenclever \& Torres, 2013).

A formação e manutenção de acordos entre firmas depende de alguns fatores. A não efetividade de conluio está associada à: maior dificuldade de detecção de violação do acordo; assimetrias na estrutura de custos, pois empresas com custos distintos tem diferentes percepções com relação a preço; maior heterogeneidade de produto, pois além das dificuldades inerentes à própria diferenciação, diferenças nos produtos levam a curvas de demanda distintas e discordância com relação a preços; e maior número de concorrentes, o que dificulta o consenso (Jacquemin \& Slade, 1996; Rocha, 2013).

Para Farina (2000), o conluio é mais viável em mercados com as seguintes características: menor número de empresas; com alto grau de concentração; que oferece produtos padronizados; onde não existam acordos secretos e que, por isso, a violação pode ser rapidamente identificada; em que mudanças técnicas são raras; em que o crescimento do mercado é pequeno; no qual existe baixa elasticidade da demanda; e em que os custos de produção são idênticos.

A concorrência em preço tende a ser favorecida em mercados com baixas barreiras à entrada, com pouca diferenciação de produto, com número grande de firmas e pouco concentrados. As práticas competitivas da firma, notadamente as estratégias de determinação de preço, de produção e propaganda, juntamente com os esforços individuais em atividades de pesquisa e desenvolvimento e diferenciação, contribuem para transformar o padrão de competição em uma dada indústria, resultando no desempenho da firma (Saes, 2009). Desta forma, as estruturas podem tanto condicionar as condutas empresariais, como também podem ser modificadas por elas, indicando importância considerável à conduta das empresas como no desenvolvimento das características de um setor.

Por fim, em termos de desempenho são avaliadas as implicações para a concorrência, como a lucratividade, que é a medida mais usada; eficiência em custo; qualidade dos produtos; progresso técnico, relativo ao processo de produção e distribuição (Lipczynski \& Wilson, 2004); bem como a contribuição para a viabilização do pleno emprego dos recursos; e a contribuição para uma distribuição equitativa da renda (Fagundes \& Pondé, 1998).

A partir da conduta das firmas, é possível explicar seu desempenho, considerando a alocação dos fatores, o emprego, a rentabilidade, o desenvolvimento e o progresso (MORVAN, 1991). Ou seja, as estratégias desenvolvidas pelas firmas, a partir da estrutura de mercado, definem sua eficiência. Para Farina (1999), o desempenho das firmas pode ser simplificado em duas importantes diretrizes: sobrevivência ou crescimento. Dessa forma, o desempenho dos agentes está diretamente relacionado ao seu comportamento em termos de estratégia, que, por sua vez, está relacionado às estruturas de mercado, como já mencionado.

Observa-se ainda que as políticas públicas também desempenham o seu papel, influenciando a estrutura de mercado e a conduta das firmas. As agências governamentais podem intervir por meio da aplicação de medidas políticas para corrigir alguns aspectos do mercado. Vários são os instrumentos que podem ser utilizados para influenciar o mercado, como impostos e subsídios, políticas que afetam o mercado internacional, regulação, controle de preços, políticas antitruste, entre outros (Scherer \& Ross, 1990).

Discute-se então que, apesar de ter claras implicações estratégicas para as empresas, o arcabouço teórico da OI esteve centrado em políticas públicas, principalmente na regulamentação de setores nãoconcorrenciais (Saes, 2009). As leis antitruste ou leis de defesa da concorrência foram criadas com a finalidade de garantir a existência de condições de competição, preservando ou estimulando ambientes competitivos que visem maior eficiência econômica (Mello, 2013).

Mais recentemente, devido a críticas ao paradigma linear ECD, houve uma evolução das análises no campo da OI, ficando conhecida como "Nova Organização Industrial". Dentre outros aspectos, a Nova Organização Industrial está focada mais na conduta discutida no modelo ECD, ou seja, examina o comportamento das firmas (Jacquemin, 2000). O comportamento está voltado à definição de estratégias para a firma com vistas a enfrentar a concorrência do mercado.

Sendo assim, discute-se que, apesar das críticas, a identificação de todas essas condições do modelo é importante no delineamento da indústria, para entender $\mathrm{o}$ funcionamento dos mercados $\mathrm{e}$ consequentemente as estratégias utilizadas pelas empresas. Portanto, estudar as estruturas de mercado 
permite a compreensão das diferentes condutas adotadas pelas firmas com relação a preço, produção, inovação e publicidade. As firmas definem suas estratégias a partir das estruturas do mercado da qual fazem parte.

Para melhor fundamentar este estudo, o próximo tópico apresenta questões sobre as estratégias das firmas e o oligopólio competitivo.

\section{As estratégias das firmas e o oligopólio competitivo}

As discussões sobre o embasamento teórico da análise das estratégias das firmas tiveram origem nos anos de 1930 com o surgimento da OI. Sua abordagem sobre setores industriais conduziu a avanços importantes para a compreensão da estratégia competitiva. Anos depois, passou-se a incorporar de maneira sistemática a análise econômica baseada nas ferramentas da teoria de OI para formulação teórica de estratégia, sobretudo nos trabalhos de Chandler e Porter (Saes, 2009).

O modelo de Porter (1980) propôs técnicas para fazer análise competitiva e da indústria. Seu modelo tornou-se um marco na análise do planejamento estratégico, tendo na OI um suporte metodológico (Saes, 2009). Os estudos de Porter basearam-se na análise do setor concorrente, nas barreiras de entrada, em estratégias genéricas, na produção de valor e de cadeia de valor e de produtos substitutos (Porter, 1980).

Observa-se que sua preocupação considera questões estruturais discutidas pelo modelo ECD, portanto torna-se importante estudar temas como a concorrência, barreiras de entrada e produtos substitutos, para entender o funcionamento da indústria e dos mercados. A concorrência é o fenômeno mais característico das economias capitalistas, apesar da complexidade de seu conceito, ela pode ser considerada como um jogo de disputas de parcelas de mercado (Hasenclever \& Kupfer, 2013). Dependendo da concorrência (ou estrutura de mercado), as empresas precisam adotar diferentes estratégias para conquistar seu espaço.

As barreiras de entrada podem ser vistas como a facilidade ou a dificuldade de entrada em determinada indústria. Conhecer tanto as barreiras de entrada, quanto as barreiras de saída são importantes para determinar a lucratividade das firmas no curto e longo prazo, pois esse fluxo caracteriza a natureza e a força da competição no mercado. As barreiras podem ser legais ou estruturais. As principais barreiras legais são: (1) a necessidade de registro, certificação e licenças; (2) direitos de monopólio; (3) patentes; e (4) políticas governamentais. As barreiras estruturais podem ser advindas de três principais: (1) economias de escala e escopo; (2) vantagens absolutas de custo; e (3) diferenciação de produto (Fagundes \& Pondé, 1998; Lipczynski, Wilson, \& Goddard, 2009).

$\mathrm{Na}$ indústria, os custos são fatores condicionantes para crescimento e desenvolvimento.
As fontes de vantagem em custo variam e dependem da estrutura da indústria, podendo incluir a busca de economias de escala, tecnologia patenteada, acesso a matéria prima, entre outros. Um líder em custo pode obter ganhos acima da concorrência se conseguir sustentar a liderança em custo e manter os preços na média da indústria ou perto dela (Porter, 1990). O preço torna-se mais preocupante quando existem muitos produtos substitutos.

Os produtos considerados substitutos são aqueles suficientemente próximos, nos quais o consumidor consegue trocar um pelo outro, tomando por base a análise do preço e da qualidade para fazer sua escolha (Farina, 1999). Quando não existe diferenciação do produto no mercado, as empresas são tomadoras de preços, pois os consumidores considerando os produtos idênticos optam por adquirir os produtos de menor valor. No entanto, na prática os produtos dificilmente são idênticos, as empresas buscam uma diferenciação para poder influenciar o preço dos produtos. Os produtos podem ser diferenciados por local de oferta, qualidade e marca (Losekann \& Gutierrez, 2013).

De modo geral, pode-se classificar as estratégias como: (1) estratégia de preço, que podem envolver preço de dissuasão de entrada, preços de colusão, liderança em preço e discriminação de preço; e (2) estratégias não preço, que incluem diferenciação do produto, publicidade e propaganda e investimento em pesquisa e desenvolvimento (Lipczynski, Wilson, $\&$ Goddard, 2009).

Scherer and Ross (1990) identificaram quatro principais formas de diferenciação de produtos: (1) local mais conveniente do que o concorrente; (2) diferenças físicas no produto, como design; (3) produtos ou serviços excepcionalmente melhores; e (4) imagens subjetivas na mente do consumidor. Observase que para diferenciar seus produtos e alcançar um melhor desempenho, as empresas podem investir em estratégias de marketing, propaganda e inovação, evidenciando quais vantagens ela apresenta frente ao concorrente.

$\mathrm{O}$ investimento em pesquisa e desenvolvimento está diretamente ligado à inovação, que se tornou uma importante fonte de vantagem competitiva para as organizações. Para Freeman e Soete (2008), as inovações são cruciais para sustentar ou acelerar o crescimento econômico, portanto as firmas podem diferenciar-se investindo em pesquisa e desenvolvimento e formando redes de colaboração para inovar. Enfim, são diversas as estratégias que podem ser desenvolvidas pelas firmas e elas estão em constante mudança, o que mostra um caráter circular que depende das inúmeras informações do ambiente.

É importante ressaltar que o comportamento estratégico das firmas também pode influenciar a estrutura de mercado da indústria (Scherer \& Ross, 1990; Farina, 2000), principalmente considerando o tamanho das firmas e as condutas desenvolvidas por elas. Por esse motivo, discute-se o caráter mutável das 
relações dentro do modelo ECD. Desta maneira, acredita-se que a obtenção de informações a respeito da indústria a qual a empresa está inserida pode implicar em maiores probabilidades de desenvolvimento de estratégias que beneficiem a firma.

A partir de modelos de análise dos mercados, a OI discute as características de mercados de concorrência perfeita em um extremo e de monopólio no outro. Ao se considerar os mercados oligopolizados, caracterizados por concorrência imperfeita, Possas (1987) apresenta que no oligopólio competitivo, objeto de estudo no presente trabalho, o objetivo das empresas do núcleo é ampliar as fatias de mercado; porém, as empresas marginais são resistentes à eliminação, pois suas estruturas de custo tendem a ser fortemente competitivas. As empresas na margem tendem a focar na sobrevivência. As vantagens competitivas são obtidas em virtude da capacidade de algumas empresas em permanecer no mercado mesmo em períodos de retração ou crescimento, proporcionadas pelas vantagens de custos. Alguns exemplos de empresas situadas nesta estrutura são as do setor alimentício, têxtil e calçadista, assim como produtos intermediários de pouca exigência tecnológica e/ou de escala mínima produtiva.

Conforme destacado por Possas (1987), este tipo de mercado é caracterizado por grande heterogeneidade técnica, tecnológica e de escala entre as firmas, o que resulta em baixas barreiras à entrada, economias de escala relativamente inferiores e pouca diferenciação de produto. Assim, a concorrência se dá tipicamente por preço; entretanto, outras formas de controle de mercado pelas grandes firmas podem emergir, especialmente na comercialização e no suprimento de matérias-primas, assim como em esforços para redução de custos e melhoria técnica de produto (Possas, 1987). Dessa forma, esforços de diferenciação podem levar à concorrência não preço e ampliação da fatia de mercado pelas empresas do núcleo.

O estudo de Farina, Nunes e Monteiro (2005) evidenciou que no varejo supermercadista, apesar da alta concentração do núcleo dominante, existe forte competição entre os pequenos varejistas e supermercados independentes e as grandes cadeias, que trazem ganhos em produtividade e custos ao consumidor. Portanto, seria interessante o incentivo à manutenção da franja competitiva (CHEN, 2003). Beiral, Moraes e Bacchi (2013) estudaram a possibilidade de concentração e poder de mercado na distribuição de etanol entre os anos de 2003 e 2010 e concluíram que os distribuidores não exercem efetivamente poder de mercado, sendo que a conduta se aproximou mais da concorrência perfeita que do monopólio.

Apesar de caracterizar a conduta de forma geral, esses estudos não avançaram nas estratégias utilizadas pelas firmas. Sendo assim, este estudo pretende preencher esta lacuna e mostrar como as estratégias operam na franja.

\section{PROCEDIMENTOS METODOLÓGICOS}

A presente pesquisa classifica-se como de natureza qualitativa (Denzin \& Lincoln, 1994), do tipo descritiva (Triviños, 2010), pois pretende-se estudar em profundidade as estratégias utilizadas pelas empresas estudadas frente à estrutura de mercado da indústria de baterias automotivas.

Optou-se por estudar quatro empresas situadas no estado do Paraná. A escolha justifica-se devido ao fato do estado ser citado como um dos que concentram a maior parte dessa atividade no Brasil (Castro, Barros, \& Veiga, 2013).

Para tanto, foi realizada uma coleta de dados secundários a partir de relatórios da indústria de baterias automotivas, documentos das firmas e diversos websites, como o das empresas estudadas, de associações, órgãos de classe e empresas concorrentes. Também foi realizada uma coleta de dados primários, construído por meio de entrevistas semiestruturadas (Fontana \& Frey, 1994) com os diretores das firmas. Foram realizadas quatro entrevistas, uma em cada firma. Os entrevistados foram os diretores, que participam do desenvolvimento de estratégias da empresa.

Dado que as empresas são familiares, de capital fechado e de porte relativamente reduzido, a realização de entrevistas com mais de um entrevistado não foi possível, uma vez que somente um indivíduo na empresa (sócio proprietário) dominava o conteúdo pertinente às questões estratégicas, dificultando o processo de triangulação das informações neste sentido. Entretanto, a validade e confiabilidade da pesquisa foram respaldadas devido ao fato das firmas terem suas participações já consolidadas, com tempo de atuação no mercado variando de 20 a 60 anos. Ressalta-se ainda que os entrevistados têm ampla experiência no ramo de baterias automotivas, atuando neste mercado em média há 30 anos, sendo que o mais novo já atua há pelo menos 10 anos, o que intensifica o conhecimento dos mesmos.

A definição das entrevistadas se deu por acessibilidade e o número de entrevistados teve como critério a convergência das informações. As entrevistas foram realizadas pessoalmente e no ano de 2014 com duração de aproximadamente 40 minutos cada. As entrevistas foram gravadas e transcritas na íntegra, para posterior análise.

O instrumento de coleta de dados foi dividido em três partes: a primeira com questões gerais acerca da criação da empresa e formação do entrevistado, bem como das dificuldades do processo de fabricação; a segunda parte envolveu questões sobre o mercado relevante da empresa e da concorrência neste setor; a terceira parte buscou investigar as estratégias desenvolvidas pela empresa, envolvendo a estratégia de preços e as estratégias não preço (estratégia de diferenciação, pesquisa e desenvolvimento, estratégia de inovação e estratégias de marketing), bem como seus motivadores e limitações. 
Considerando o modelo ECD, a segunda parte do roteiro auxilia na caracterização da estrutura de mercado e das condições de base da oferta e da demanda, juntamente com os dados secundários. A terceira parte, evidencia a conduta das firmas. Não foram realizadas pesquisas sobre o desempenho econômico das firmas, pois o foco estava mais na conduta, todavia pelo tempo de atuação, bem como pelas estratégias utilizadas, foi possível categorizar o desempenho das mesmas.

Para análise dos dados, foi utilizada a técnica de análise qualitativa de conteúdo (Mayring, 2000), na qual os dados foram categorizados, revisados e interpretados de acordo com a teoria estudada. As categorias emergiram do modelo ECD: condições de base a oferta, condições de base da demanda, estrutura de mercado, conduta estratégica e desempenho.

Destaca-se que os dados foram analisados e apresentados de maneira agregada, para evitar a identificação dos entrevistados. Adota-se essa postura devido a critérios éticos, para não criar possíveis atritos na referida indústria, principalmente por causa da ligação estreita entre as empresas.

\section{APRESENTAÇÃO E ANÁLISE DOS RESULTADOS}

Tabela 1 - Produção e vendas de baterias automotivas em milhões de unidades

\begin{tabular}{|c|c|c|c|c|c|c|c|c|}
\hline & $\mathbf{2 0 0 5}$ & $\mathbf{2 0 0 6}$ & $\mathbf{2 0 0 7}$ & $\mathbf{2 0 0 8}$ & $\mathbf{2 0 0 9}$ & $\mathbf{2 0 1 0}$ & $\mathbf{2 0 1 1}$ & $\mathbf{2 0 1 2}$ \\
\hline Produção & 14,39 & 14,53 & 14,50 & 16,71 & 16,73 & 18,98 & 20,05 & 18,93 \\
\hline Vendas & 13,08 & 14,31 & 13,79 & 16,09 & 16,19 & 18,63 & 18,56 & 18,74 \\
\hline
\end{tabular}

Fonte: Autores com base em IBGE/PIA-Produto (2015)

Observa-se que, apesar da produção ter crescido pouco entre 2005 e 2007, a partir de 2008 o segmento retomou a tendência de crescimento. Essa tendência deve-se à grande frota de veículos existente no país e ao aumento da fabricação e venda de veículos novos, pois a demanda de baterias automotivas está relacionada ao mercado de veículos automotores (Castro, Barros, \& Veiga, 2013). Apesar de 2012 ter uma leve queda de fabricação, as vendas continuaram seguindo o patamar dos anos anteriores. Portanto, estima-se a tendência de pequena oscilação ascendente no mercado de baterias automotivas.

Com base nas informações dos entrevistados, esse mercado sofre ligeira influência sazonal. As oscilações nas vendas ocorrem devido ao clima, pois no inverno aumenta um pouco a demanda, portanto entre os meses de setembro e outubro, término do inverno e começo do verão, as vendas apresentam pequenas quedas.

De acordo com os dados da Pesquisa Industrial Anual [PIA-empresa] do IBGE, considerando as empresas industriais com 30 ou mais pessoas ocupadas em torno de 40 empresas fabricantes de baterias no Brasil (IBGE/PIAempresa, 2011). Com relação aos vínculos empregatícios, de acordo com dados da Relação Anual de Informações Sociais [RAIS], em 2013, os vínculos formais totalizaram 9367 empregos, sendo que São Paulo gerou 46\%, o Paraná 17 $\%$; Pernambuco 15\%, Santa Catarina $12 \%$ e a soma dos demais estados fica em torno de 10\% (IBGE/RAIS, 2015).

Enfatiza-se que nove das 20 maiores empresas no setor estão localizadas no Paraná. Ao se excluir as empresas do núcleo, uma vez que o foco da pesquisa é a franja desse mercado, observa-se que metade dessas empresas estão no Paraná, o que justifica esse recorte geográfico. Diante disso, observa-se a importância da representação do estado para o setor. O quadro 1 apresenta um panorama dos principais fabricantes de baterias instalados no país. 


\begin{tabular}{|c|c|c|c|c|}
\hline Empresa & Marcas & $\begin{array}{l}\text { Origem de } \\
\text { capital }\end{array}$ & Localização & $\begin{array}{l}\text { Mercado de } \\
\text { atuação }\end{array}$ \\
\hline Moura & Moura, Zetta & Brasil & $\begin{array}{l}\text { Belo Jardim (PE), } \\
\text { Itapetininga (SP) }\end{array}$ & $\begin{array}{l}\text { OEM, reposição, } \\
\text { exportação }\end{array}$ \\
\hline $\begin{array}{l}\text { Johnson } \\
\text { Controls } \\
\end{array}$ & $\begin{array}{l}\text { Heliar, Bosch, Optima, Varta, } \\
\text { Freedom }\end{array}$ & EUA & Sorocaba (SP) & $\begin{array}{c}\text { OEM, reposição, } \\
\text { exportação }\end{array}$ \\
\hline Ajax & Ajax & Brasil & Bauru (SP) & $\begin{array}{l}\text { Reposição, } \\
\text { exportação }\end{array}$ \\
\hline Cral & Cral & Brasil & Bauru (SP) & $\begin{array}{l}\text { Reposição, } \\
\text { exportação }\end{array}$ \\
\hline Tudor & Tudor & Brasil & $\begin{array}{c}\text { Bauru (SP), } \\
\text { Governador } \\
\text { Valadares (MG) }\end{array}$ & $\begin{array}{l}\text { Reposição, } \\
\text { exportação }\end{array}$ \\
\hline Baterax & Baterax, Woltrax, Energex & Brasil & Umuarama (PR) & Reposição \\
\hline Camarotto & Camarotto & Brasil & Marmeleiro (PR) & Reposição \\
\hline Eletran & Eletran & Brasil & Apucarana (PR) & Reposição \\
\hline Enerbrax & Route & Brasil & Bauru (SP) & Reposição \\
\hline GNB & Reifor, Herbo, Yokohama & Brasil & Londrina (PR) & Reposição \\
\hline Inbracell & Excell & Brasil & Cachoeirinha (RS) & Reposição \\
\hline Júpiter & Júpiter & Brasil & Cianorte (PR) & Reposição \\
\hline Kania & Kondor, Fort Light, Dutra & Brasil & Rafard (SP) & Reposição \\
\hline Newpower & Fulguris & Brasil & Guarulhos (SP) & Reposição \\
\hline Pioneiro & $\begin{array}{c}\text { Pioneiro, Piovox, Conectiva, } \\
\text { Arazzo } \\
\end{array}$ & Brasil & Treze Tílias (SC) & Reposição \\
\hline Ranger & Extranger & Brasil & Apucarana (PR) & Reposição \\
\hline Rondopar & Max, Fox, Impact, Prac & Brasil & Londrina (PR) & Reposição \\
\hline Baterlife & Maxion & Brasil & Pinhalzinho (SC) & Reposição \\
\hline Freelight & Freelight & Brasil & $\begin{array}{l}\text { São José dos } \\
\text { Campos (SP) }\end{array}$ & Reposição \\
\hline Erbs & Erbs & Brasil & Botuverá (SC) & Reposição \\
\hline HF & HF, Globo, Delta & Brasil & Rolândia (PR) & Reposição \\
\hline Real & Real, Suprema, Forza, Discbal & Brasil & Realeza (PR) & Reposição \\
\hline
\end{tabular}

Quadro 1 - Principais fabricantes de baterias automotivas instalados no Brasil Fonte: Autores com base em Castro, Barros e Veiga (2013), ENBAT (n.d) e website das empresas

Dos principais fabricantes, nota-se a concentração das empresas em São Paulo e no Paraná, bem como uma maior concorrência no mercado de reposição. No mercado de OEM foi constatada a atuação regular apenas das duas empresas líderes de mercado. Quanto à exportação, somente foi evidenciada a prática frequente em cinco empresas. Embora acredita-se que esporadicamente outras empresas também façam exportação, como é o caso de três das empresas estudadas.

Apesar do número de empresas atuantes nesse setor, algumas restrições de entrada e permanência no mercado formal foram observadas, como os requisitos de investimento para atuar nesse mercado, principalmente de máquinas e equipamentos. Os investimentos iniciais e os custos fixos influenciam a estrutura de custos dessas empresas, exigindo uma 
escala mínima para alcançar a eficiência, o que a literatura aponta como uma barreira estrutural à entrada (Fagundes \& Pondé, 1998; Lipczynski, Wilson, \& Goddard, 2009).

Outro fator a ser considerado para explicar o número reduzido de empresas está relacionado a rigorosa legislação ambiental. Devido à periculosidade do chumbo, matéria prima para confecção de baterias, que é prejudicial tanto à saúde humana quanto ao meio ambiente, esse mercado é altamente fiscalizado por órgãos como: o Instituto Brasileiro do Meio Ambiente e dos Recursos Naturais Renováveis [IBAMA], que tem por principal atribuição exercer o poder de polícia ambiental (IBAMA, n.d); e o Instituto Ambiental do Paraná [IAP] que exerce o poder de polícia administrativa, controle, licenciamento ambiental para instalação, operação e ampliação de atividades poluidoras ou perturbadoras do meio ambiente (IAP, n.d).

Além disso, devido à Política Nacional de Resíduos Sólidos [PNRS] sancionada em 2 de agosto de 2010 pela Lei 12.305, os fabricantes de baterias precisam prestar contas dos resíduos deixados por essa atividade. Por isso, devem seguir a Resolução do Conselho Nacional do Meio Ambiente [CONAMA] $n^{\circ}$ 401 de 4 de novembro de 2008 que estabelece os limites de chumbo para as baterias comercializadas no país; e a Instrução Normativa IBAMA n 8 de 30 de setembro de 2012 que institui os procedimentos de recebimento e destinação final das baterias (IBAMA, n.d).

Em 2013, ainda foi criada uma legislação específica para a fabricação de baterias pelo Instituto Nacional de Metrologia, Qualidade e Tecnologia [INMETRO], a portaria n ${ }^{\circ} 299$ de 14 de junho de 2012, que entrou em vigor em junho de 2013 e a partir de 14 de dezembro de 2013 é proibido comercializar bateria que não esteja dentro das especificações requeridas por lei, como por exemplo, identificar no rótulo: o peso, os dados de amperagem, quantidade de placas e o fabricante (INMETRO, 2012). Portanto, acredita-se que essas exigências podem ser consideradas como uma barreira legal à entrada (Fagundes \& Pondé, 1998; Lipczynski, Wilson, \& Goddard, 2009), influenciando a estrutura desse mercado.

Ressalva-se que os dados oficiais sobre as empresas no setor excluem aquelas que atuam na informalidade. Dadas as barreiras de entrada associadas aos investimentos iniciais e a rigorosa legislação, bem como a facilidade de atuação no mercado informal, muitos concorrentes atuam na clandestinidade. Portanto, ainda que oficialmente exista um número restrito de empresas na franja, estima-se uma considerável quantidade de empresas informais, o que indica a existência de um número muito maior de empresas de menor porte competindo no mercado de reposição.

A partir dessas características da estrutura de mercado, passe-se agora para a análise das estratégias das firmas.

\section{Estratégias das empresas frente à estrutura de mercado}

As empresas selecionadas para estudo estão localizadas no Estado do Paraná. Todas se enquadram dentro das normas legais requeridas e possuem bastante conhecimento sobre o mercado. Em média as organizações apresentam uma produção mensal em torno de 60.000 unidades e possuem cerca de 220 funcionários. Três das empresas atendem todo o Brasil, sendo que duas alegam fazer exportações esporádicas a países do MERCOSUL. Apenas uma das organizações não está presente em todo o país, porém atende cerca de metade dos estados brasileiros.

Destaca-se que as quatro empresas estão entre os principais fabricantes do país citados anteriormente e atuam há mais de 20 anos no setor. Outro fator a ser considerado é que todos os fabricantes possuem relacionamentos de longo prazo entre si. Um dos entrevistados, que é sócio proprietário de uma das organizações, já trabalhou em duas das outras empresas pesquisadas. Ele também trabalhou em outra grande empresa de São Paulo e afirma conhecer a maioria dos fabricantes brasileiros. Isso pode influenciar o padrão de concorrência entre as firmas, direcionando as estratégias para cooperação, ainda que tácita (Jacquemin \& Slade, 1996; Rocha, 2013).

Com relação à concorrência, todos os entrevistados alegam que o mercado é muito concorrido. De modo geral, este mercado pode ser considerado um oligopólio competitivo (Possas, 1987; Farina, 1999), com elevada concentração nas duas grandes empresas, tanto no mercado de OEM quanto no de reposição. E a existência de uma franja competitiva formada pelas demais firmas que atuam no mercado de reposição.

Segundo os entrevistados, a maior dificuldade para atuação nesse mercado é competir com o mercado informal, fator que torna a concorrência desleal. Os entrevistados revelam que o mercado informal atrapalha devido ao alto investimento dos fabricantes no mercado formal, eles precisam investir em certificações e cumprir a legislação ambiental, comportamento que não é cumprido pelas empresas informais. Ressalta-se, assim, a grande heterogeneidade nesse setor, típica de oligopólios competitivos (Possas, 1987), em que coexistem desde empresas de grande porte, com avançado padrão tecnológico, até pequenas empresas informais, com padrão técnico, tecnológico e de escala consideravelmente reduzido.

Apesar da dificuldade existente na fabricação de baterias, o produto pode ser equiparado a uma commodity, pois o cliente pode não perceber sua qualidade e tende a se orientar pelo preço. Reforça-se a pouca diferenciação de produto nesse tipo de mercado, conforme apontado por Possas (1987). Como observado no exemplo citado por um dos entrevistados: 
o mercado tem uma demanda, enquanto haja oferta, por mais que seja ruim, prejudica, porque se tem 100 pessoas que precisam de bateria, e se tem 15 de 'fundo de quintal' sobra 85 , porque seguramente essas 15 vão ser vendidas, porque tem um preço menor.

Os entrevistados ainda citam que nesse mercado existe muita propaganda enganosa, pois a bateria precisa de um número mínimo de placas (importante componente do produto) para alcançar a amperagem necessária. Neste caso, algumas empresas informam no rótulo do produto determinada amperagem; contudo, quando analisadas, o número de placas é insuficiente para atingir essa amperagem. Logo, o rótulo do produto não coincide com a realidade ofertada pela empresa, porém o cliente não tem como conhecer todas essas especificidades, sendo esse um atributo de crença. Portanto, segundo os entrevistados, os fabricantes que realmente trabalham com um produto dentro das normas acabam concorrendo em desigualdade com essas empresas, devido ao seu custo mais alto.

Observa-se que as empresas no mercado formal são pressionadas pela concorrência com as empresas informais, que apresentam diferenças em termos de estrutura de custos e enfrentam barreiras à entrada e à saída diferentes. Desta forma, esforços para reduzir essa falha de informação, tais como certificações e selos que garantam a composição do produto, devem ser estimulados, funcionando inclusive como um mecanismo de diferenciação de produto frente à concorrência no mercado informal. Nesse sentido, todos os entrevistados concordam que com a normatização do INMETRO essa prática tende a acabar, pois as empresas serão obrigadas a identificar corretamente o produto e o consumidor terá como compará-los. Eles acreditam que essa normatização pode "moralizar" o mercado, favorecendo também o entendimento do consumidor sobre o produto. Observa-se que a regulação deve trazer influência na conduta competitiva das firmas, conforme preconiza a teoria.

Antes da normatização, os entrevistados asseguram que faltavam informações importantes no rótulo sobre o produto, cada fabricante colocava as especificações da forma que acreditava ser conveniente, o que também dificultava a comparação. A partir dezembro de 2013, o INMETRO padronizou as informações necessárias. Porém, um dos entrevistados ainda está temeroso quanto à realização da fiscalização do INMETRO, devido principalmente ao alto custo dos testes existentes para comprovação das especificações do produto.

Em relação às dificuldades em trabalhar na fabricação de baterias automotivas, todos os entrevistados apresentam a questão da compra de sucata. Como citado anteriormente, a fabricação depende da reciclagem de chumbo, que é sua matéria prima, portanto utiliza-se da logística reversa. A reciclagem de sucata de baterias é obrigatória devido à resolução do CONAMA, que obriga a devolução da bateria usada para a compra de uma nova. Todavia, como a sucata tem valor de mercado, esse produto é comercializado, sendo parte do pagamento feito pelos distribuidores na compra de baterias novas. Normalmente o distribuidor armazena as baterias usadas que recolhe do consumidor e na compra de baterias novas envia a sucata como parte da negociação.

O problema da quantidade de placas também atrapalha no momento da reciclagem da sucata, conforme um entrevistado "hoje você recolhe uma dessas que não é 60 (amperes), cada três baterias que você recolhe, dá para fazer uma do INMETRO". Neste caso, falta matéria prima e a empresa precisa comprar chumbo, que na maioria das vezes precisa ser importado, sendo cotado em dólar. Observa-se que a principal dificuldade para fabricação deriva da negociação de sucata e sofre influência da concorrência.

Todas essas questões implicam dinâmicas particulares de concorrência nesse setor, tornando-o bastante específico, fato que não ocorre no mercado de OEM. Por conta dessas especificidades, os fabricantes formais, de modo geral, incluindo as empresas do núcleo, participam de encontros e reuniões para discutir estratégias, ações e parcerias, tentando diminuir os impactos da concorrência informal. Reforça-se aqui a possibilidade de cooperação em grupos estratégicos, para sobrevivência ou crescimento no setor.

Contudo, foi apontado por um entrevistado que a falta de união dos fabricantes torna-se uma dificuldade de atuação por estratégia cooperativa. Ele acredita que os diversos encontros do setor são importantes para discutir estratégias que visem valorizar o produto e o mercado. No entanto, na sua visão, essas reuniões e discussões não se concretizam em ações conjuntas, pois na prática a concorrência por preço acaba sendo o balizador das negociações. Todos os entrevistados acreditam que, em média, o preço praticado fica abaixo do ideal para manter toda a estrutura da empresa. Um deles confirma essa situação argumentando sobre a dificuldade de aumentar os preços, "nos últimos anos o preço deveria aumentar mais, às vezes os fabricantes são um pouco temerosos". Observa-se claramente a concorrência em preço, típica na franja de oligopólios competitivos, como destaca Possas (1987).

No intuito de lidar com essas dificuldades apontadas, as empresas, de modo geral, tentam argumentar sobre a qualidade e confiabilidade dos seus produtos pelo tempo no mercado e experiência no ramo. Tentando diferenciar-se, as empresas destacam algumas iniciativas como: (1) investir na redução de custos por meio da automação; (2) apresentar uma baixa porcentagem de devolução por causa de defeitos; 
(3) investir em selos de qualidade e ambiental, como ISO 9000; (4) qualificação da mão de obra especializada, por meio de cursos internacionais; (5) busca de vantagens logísticas; e (6) trabalhar a qualidade e confiabilidade da marca.

Apesar dessas iniciativas destacadas pelos entrevistados, percebe-se a prevalência da concorrência por preço. Todos os entrevistados frisam a importância dessas ações, porém as encaram como uma necessidade e no fim voltam a assegurar que a negociação de preço precisa ser estabelecida e discutida com o cliente com frequência. Um dos entrevistados destaca essa necessidade de negociação para manter os clientes, afirmando que por vezes precisa baixar o preço para fechar a venda, "você é obrigado a sobreviver, você é obrigado a se apertar para não perder o cliente, pois tem responsabilidades, chega no final do mês tem que fechar as contas". Isto mostra que o desempenho dessas empresas está atrelado a sobrevivência, conforme destaca Farina (1999).

Constata-se então que no mercado de reposição não há significativa diferença entre os produtos, sendo que as empresas competem por meio da redução de custos, conforme um dos entrevistados.

Nós estamos hoje nas mesmas condições, apesar que nós compramos uma máquina automática de fabricar placa que é uma das melhores do mundo [...] nós investimos três milhões de dólares, está funcionado a todo vapor, então o nosso custo vai ser menor, nós temos condição de brigar mais no preço. Hoje está todo mundo no mesmo patamar de produto. Não tem como o cara falar: ah minha bateria dura dez anos, não. Está tudo na média.

Por conseguinte, observa-se que a maior estratégia das empresas é investir em automação para tentar otimizar a produção e com isso conseguir melhorar a qualidade. A qualidade, neste mercado, é vista por meio da durabilidade do produto e da redução de custos mantendo padrões. Percebe-se a importância do custo para adquirir parcela de mercado, pois as empresas não têm grande influência nos preços praticados, dada a baixa diferenciação do produto.

Nesse contexto, os entrevistados concordam que a estratégia de preço segue a oscilação e determinação do mercado. No entanto, reforçaram a necessidade de considerar os custos de fabricação para precificar, como: custos fixos; variação do preço da matéria prima (chumbo, sucata); necessidade de renovação recorrente de maquinário; custos ambientais, que envolvem programas de sustentabilidade ambiental; e uma margem de lucro.

Comparando os preços com a concorrência na franja, os entrevistados acreditam que os preços praticados são semelhantes, porém frisam que não podem ser comparados com aqueles que trabalham no mercado informal, cujas especificações estão fora das normas e padrões. A afirmação de um dos entrevistados representa bem as condições de concorrência por preço: "nós atuamos no mercado de reposição [...], então é sempre tudo igual, é coisa de um ou dois reais de diferença, porque todo mundo está na mesma condição, o preço que ele paga na sucata eu também pago, tudo que ele tem eu também tenho".

Quando perguntado sobre pesquisa, desenvolvimento e inovação, os entrevistados declaram que é necessário mudar constantemente e que houve muita evolução nesse mercado nos últimos anos. Existem algumas redes de pesquisa que trabalham para desenvolvimento deste setor, como o Instituto de Tecnologia para Desenvolvimento [LACTEC], que é um centro de pesquisa tecnológica sem fins lucrativos (LACTEC, n.d); e a Universidade Federal de São Carlos (UFSCar). Essas instituições, em parceria com os fabricantes, promovem o Encontro Nacional de Produtores de Baterias Chumbo-Ácido [ENBAT], com o objetivo promover a interação entre os produtores de baterias chumbo ácido, fornecedores, universidades e centros de pesquisa (ENBAT, n.d). Outra iniciativa é a Feira Nacional e Internacional de Baterias de Chumbo [FENIBAT], com intuito de fortalecer toda a cadeia produtiva e estimular os negócios a nível nacional e internacional (FENIBAT, 2015). Assim, apesar de não existirem esforços de pesquisa individual pelas empresas entrevistadas, essa rede de pesquisa dá suporte a inovações no setor.

Por meio dessas redes e eventos, as empresas se atualizam e conhecem as novidades do ramo, principalmente com relação a melhorias no processo e novas máquinas e equipamentos, como citado por um dos entrevistados:

tem que estar a par do que está acontecendo no mundo. Você vê uma bateria de dez anos atrás, é completamente diferente da de hoje. Aditivos na massa para melhorar o sistema de cargas, melhoria de reações, desenho da placa, [...] acúmulo de energia da bateria, estudo da pasta com relação a densidade, umidade, dureza, reações químicas.

Percebe-se que as inovações nas empresas centram-se em melhorias no processo produtivo, visando principalmente a rapidez na fabricação e consequentemente a redução de custos. Dentre as melhorias realizadas, pode-se citar o desenvolvimento de carregadores eletrônicos e o uso de diferentes componentes químicos na massa, como prata e outros aditivos. Como as empresas precisam baixar o custo, esses investimentos são importantes para ganho de economias de escala e produtividade, como apresentado por Porter (1990).

Quando perguntado sobre as novas tecnologias que estão surgindo no mercado, como as baterias de íon-lítio (Castro, Barros, \& Veiga, 2013), os entrevistados acreditam que essas tecnologias ainda são inviáveis comercialmente, tanto no Brasil quanto no exterior, devido ao alto custo. Como afirma um deles: 
O Brasil não tem condições hoje, mesmo lá fora é muito caro, para você ver: hoje uma bateria de lítio deve custar aí dez mil reais, mesmo que dure dez anos, quem vai comprar? Então não tem viabilidade comercial. Hoje para fabricar bateria chumboácido é muito barato, você compra uma bateria por duzentos reais e dura dois anos, é quase o preço de encher o tanque do carro, que você gasta em uma semana.

Apesar de inviáveis no contexto atual, acreditase que no futuro pode haver mudanças nas condições de base da oferta, mudando todo o paradigma tecnológico e podendo impactar as empresas do setor, alterando a estrutura de mercado. No entanto, atualmente ainda há espaço para crescimento do mercado no segmento de baterias chumbo-ácido.

Por fim, com relação às estratégias de marketing (publicidade e propaganda), os entrevistados apontam tímidos investimentos, deixando a cargo do varejista o investimento em propaganda. De forma geral, as estratégias voltadas à divulgação das empresas são semelhantes, sendo citados como investimentos em marketing: folders; jalecos para atendentes em lojas e autopeças; expositores para fixar as baterias em pontos de venda; propaganda regional via rádio; jornais internos ou de circulação local; e revistas especializadas. Vale ressaltar que, com exceção do período sazonal, as empresas são normalmente procuradas pelos distribuidores e toda a produção é vendida normalmente, o que também descarta a necessidade de investimentos em marketing e propaganda, segundo os entrevistados.

De forma diferente, observa-se que as empresas do núcleo investem mais em publicidade e propaganda. Elas investem em comerciais via rádio e televisão a nível nacional, patrocinam eventos esportivos e fazem propaganda nos pontos de venda, buscando diferenciação por marca, para se afastar da concorrência em preço e ganhar fatia de mercado. Isto mostra-se de acordo com a discussão de Possas (1987).

Mediante a discussão apresentada, acredita-se que a conduta das firmas na franja, por meio das estratégias observadas, sofre influência da estrutura de mercado da indústria de baterias automotivas. Por conseguinte, essa conduta culmina em um padrão de concorrência semelhante nas organizações, que, apesar de realizarem diversas ações para desenvolvimento do produto e das empresas, acabam concorrendo por preço devido a estrutura. Observa-se assim que o foco em custo, nesse setor, depende da combinação de um conjunto de estratégias pelas firmas entrevistadas. Assim, a concorrência por preço é suportada, em grande parte, por estratégias não preço, tais como as iniciativas de inovação.

A figura 2 esboça o cenário da indústria de baterias automotivas na perspectiva do modelo ECD. 


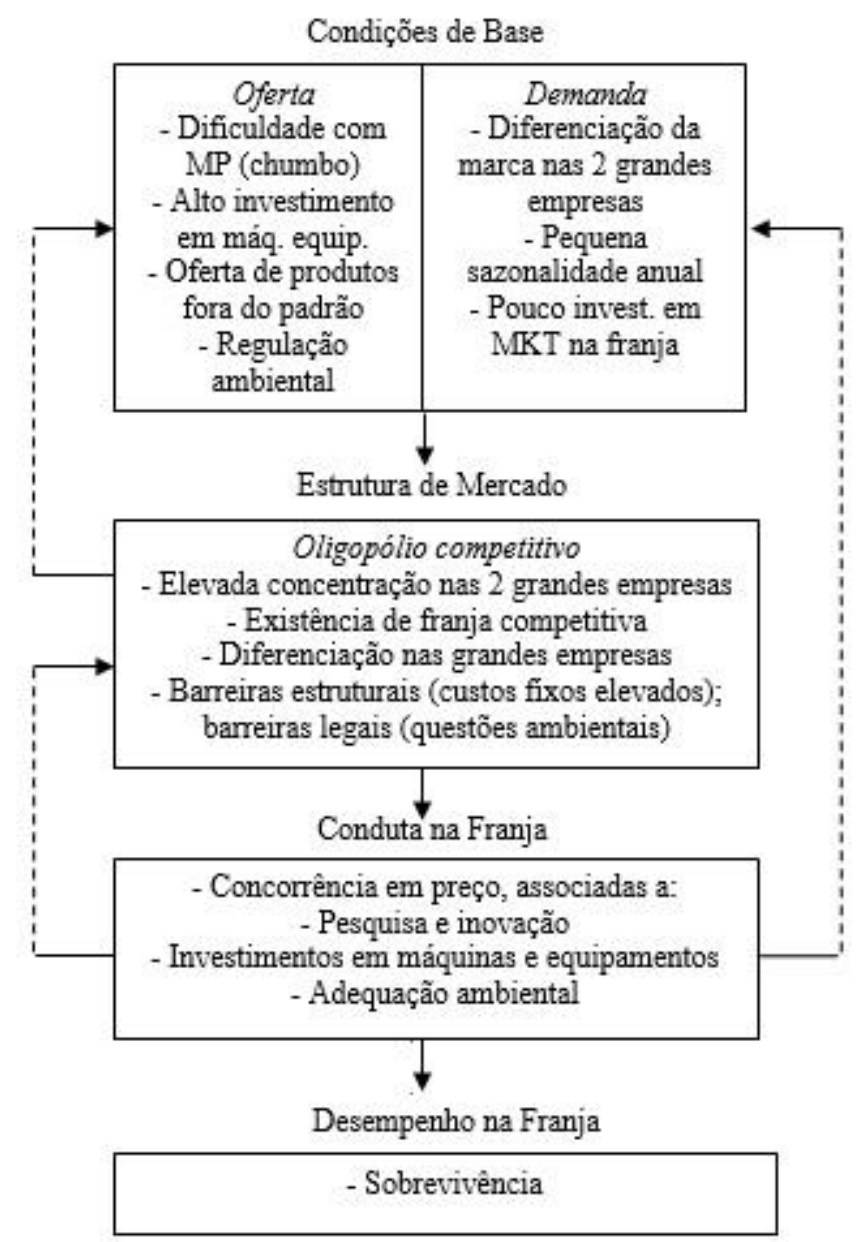

Figura 2 - Cenário da indústria de baterias automotivas na perspectiva do modelo ECD Fonte: Autores com base nos dados da pesquisa.

Ao observar a figura, pode-se perceber que as condições de base relevantes do lado da oferta são: a dificuldade de aquisição da matéria prima (chumbo) devido à necessidade de reciclagem ou importação; o constante investimento em máquinas e equipamentos que tem alto custo; a oferta de produtos fora do padrão com preço menor, que prejudica a concorrência; e a severa regulação ambiental.

Do lado da demanda, ressalta-se: pouca diferenciação do produto, sendo que os produtos das duas grandes empresas são diferenciados pela marca e as empresas na franja trabalham com um produto similar; pequena sazonalidade anual devido ao aumento da demanda no inverno; e pouco investimento em marketing, por parte dos fabricantes na franja, o que diferencia bastante das duas grandes empresas, nas quais as vendas de OEM dão grande vantagem sobre as demais.

Esses elementos são importantes na definição da estrutura, pois a necessidade de alto investimento inicial na planta de produção e os custos fixos elevados, que são consideradas barreiras à entrada, propiciam um número reduzido de fabricantes no mercado formal, se comparado aos compradores. A estrutura de mercado é caracterizada como um oligopólio competitivo, pois existem duas grandes empresas que dominam o mercado e outras empresas que trabalham na franja. Neste contexto, os produtos são diferenciados pela marca nas duas grandes empresas e não diferenciados na franja, enfatizando a concorrência por preço fora do núcleo, conforme Possas (1987). Além disso, o número reduzido de fabricantes também pode ser explicado pelas barreiras legais, por meio das exigências de órgãos como IBAMA, IAP e INMETRO. No entanto, falhas de mercado viabilizam a existência de empresas na informalidade, o que indica um número muito maior de empresas competindo no mercado.

Vale destacar outros aspectos das condições de base da oferta, que são: a existência da dificuldade de aquisição da matéria prima, que depende de logística reversa e sofre forte regulação ambiental; e a oferta de produtos fora do padrão, o mercado informal, que devido a própria severidade da regulação ambiental, 
acaba surgindo e dificultando o trabalho dos fabricantes formais. Apesar de não ter dados sobre o mercado informal, acredita-se que sua atuação é abrangente por causa da concorrência por preço nas empresas da franja.

Embora haja concorrência por preço, destaca-se que toda a produção é escoada e as empresas normalmente trabalham com capacidade instalada total. Isso ocorre devido ao fato das empresas trabalharem com preços achatados, pois uma pequena elevação no preço, dada a homogeneidade do produto, faz a firma perder mercado. Deve-se considerar ainda que grande parte do atendimento no mercado de reposição é feito pelas empresas do núcleo. Portanto, oscilações substanciais de demanda podem estar sendo atendidas pelas grandes empresas. Nas empresas da franja, há possibilidades de ajustes de médio e curto prazo para atender ao aumento da demanda, tais como horas extras, novos turnos e contratações de funcionários.

Existe pequena sazonalidade anual, porém não há muito prejuízo as vendas, o que também tem influência na pequena necessidade de investimento em marketing, que é tímido por parte das empresas da franja. Nesse sentido, aponta-se que a desempenho focado em sobrevivência favorece a adoção de estratégias desse tipo, diferentemente do que se esperaria se o desempenho das entrevistadas fosse focado em crescimento. Ainda que exista crescimento decorrente da própria expansão do setor, tal crescimento não está atrelado a ganhos de fatia de mercado, sendo meramente uma consequência da expansão do mercado.

Todas essas condições culminam numa estrutura diferenciada que, por sua vez, parece influenciar diretamente nas estratégias desenvolvidas pelas empresas na franja. Mesmo que os entrevistados enfatizem a existência de parcerias para desenvolvimento de pesquisa e inovação e alguma tentativa de diferenciação pelo apelo ambiental, as estratégias centram-se na concorrência em preço, gerando então a necessidade de grandes investimentos em capacidade produtiva para reduzir custos e gerar ganhos de escala.

Além disso, destaca-se que a elevada heterogeneidade, característica de oligopólios competitivos, é observada dentro da própria "franja", envolvendo empresas com diferentes padrões técnicos, tecnológicos e de escala, inclusive no mercado informal. Tal disparidade tem relevância no setor em dois sentidos. Primeiramente, porque envolve uma diversidade de empresas, desde empresas formalizadas de porte relativamente maior até empresas muito pequenas, que atuam na informalidade, tornando o padrão de concorrência ainda mais complexo. Segundo, porque implica no insucesso de tentativas de cooperação entre as empresas, uma vez que diferenças em termos de estrutura de custos, padrões de demanda e tecnologia podem dificultar o consenso e a definição de um objetivo comum entre as firmas.

Neste contexto, acrescenta-se a importância das políticas públicas para regular o mercado e extinguir o mercado informal, como no caso da legislação do INMETRO e de ações mais efetivas de fiscalização. A regulação auxilia no controle da concorrência informal e no fomento a condutas associadas a estratégia não preço, como as práticas de inovação e investimentos, garantindo ganhos de produtividade e custos. Isto garante a sobrevivência das firmas formais na franja, as quais influenciam no funcionamento do mercado de baterias automotivas.

Portanto, a conduta influencia no desempenho das firmas, que neste caso pode ser caracterizado como sobrevivência, conforme Farina (1999), apresentando altos custos fixos e trabalhando à margem das duas grandes empresas.

\section{CONCLUSÕES}

Ao evidenciar como as estratégias das firmas na franja se alinham à estrutura de mercado de baterias automotivas para reposição, observou-se grande complexidade competitiva, principalmente considerando a heterogeneidade das firmas na franja. A literatura normalmente apresenta dois grupos distintos, o núcleo e a franja (Possas, 1987; Farina, 1999). Entretanto, há uma heterogeneidade em termos de estrutura da firma, tamanho, escala, padrão técnico e tecnológico, entre outros, suportando inclusive a atuação de empresas no mercado informal. Isso impede a identificação de um padrão de concorrência único pelas empresas fora do núcleo.

Com relação a conduta das firmas, notou-se que a concorrência em preço, típica de firmas na franja, é suportada não só por práticas de políticas de preço e redução de custos, mas também pela combinação de estratégias não preço, como o investimento em inovação, pesquisa e desenvolvimento e qualidade. Entretanto, as estratégias não preço são direcionadas para melhorar o desempenho em custo, alinhado à concorrência em preço. Neste contexto, percebe-se que mesmo em setores ou grupos estratégicos focados em custo, políticas de fomento a práticas de inovação, qualidade e avanços técnicos devem ser enfatizadas, visando garantir ganhos de produtividade e custos.

Ressalta-se que, embora a concorrência não seja acirrada, dado o relacionamento entre os agentes e as iniciativas de cooperação, a concorrência prevalece sobre a cooperação. $O$ insucesso em se efetivar as práticas de conluio pode estar associado à grande heterogeneidade das firmas, conforme preconizado pela teoria.

Considerando a importância das políticas públicas, observou-se o seu papel para amenizar a concorrência desleal. Neste caso, as empresas formais 
Estrutura de Mercado e Estratégia: Um Estudo na Indústria Brasileira de Baterias Automotivas

são pressionadas pela concorrência com as empresas informais, que apresentam diferentes estruturas de custo e enfrentam diferentes barreiras à entrada e à saída. Além disso, pondera-se o papel da regulação ambiental no caso estudado. A regulação ambiental pode ser considerada uma barreira legal à entrada (Lipczynski, Wilson, \& Goddard, 2009), e tem relevante papel nas condições de base da oferta e na conduta das empresas. Observou-se a existência de várias normas e exigências legais que devem ser cumpridas, como o licenciamento ambiental para funcionamento, a fiscalização de órgãos como IAP e IBAMA e as normatizações como a do CONAMA e INMETRO. A necessidade de cumprimento de tais normas pode inibir a entrada de novas empresas no setor.

Por fim, destacam-se as limitações do trabalho, como o fato do trabalho ter estudado apenas empresas no Paraná. O estudo ainda limitou-se as empresas formais na franja, não incluindo as empresas do núcleo e nem empresas informais, o que poderia dar uma visão mais ampla do mercado de baterias automotivas. O trabalho também considerou o desempenho de forma simplificada, podendo a pesquisa ser ampliada posteriormente.

Diante desse quadro, surgem novos questionamentos: Como se dá a concorrência no mercado informal? Como as duas grandes empresas líderes de mercado enxergam esse panorama? Quais estratégias elas utilizam para manter a liderança e impedir a atuação de outras empresas no mercado de OEM? Além disso, perante o arrefecimento do mercado, como tais empresas passarão efetivamente a competir? Considerando o grande investimento em tecnologia, em caso de mudança do paradigma tecnológico, como essas empresas reagirão frente as novas tecnologias? Sendo assim, acredita-se que novas pesquisas devem ser realizadas no intuito de responder a essas indagações.

\section{REFERÊNCIAS}

Anh, T. T., Binh, D. T. T., \& Duong, N. V. (2014, June). The structure-conduct-performance paradigm revisited: an empirical analysis for Vietnamese firms. Proceedings of the VEAM: Vietnam Economists Annual Meeting, Ho Chi Minh City, Vietnam, 7.

Bain, J. S. (1959). Industrial organization, New York: John Wiley \& Sons.

Beiral, P. R. S., Moraes, M. A. F. D., \& Bacchi, M. R. P. (2013). Concentração e poder de mercado na distribuição de etanol combustível: análise sob a ótica da nova organização industrial empírica. Economia Aplicada, 17(2), pp. 251-274.
Cabral, L. M. B. (2000). Introduction to industrial organization. MIT Press.

Castro, B. H. R., Barros, D. C., \& Veiga, S. G. (2013). Baterias automotivas: panorama da indústria no Brasil, as novas tecnologias e como os veículos elétricos podem transformar o mercado global. BNDES Setorial, mar. p. 443-496. Recuperado em 06 outubro, 2013 de http://www.bndes.gov.br/SiteBNDES/bndes/bndes_ pt/Institucional/Publicacoes/Consulta_Expressa/Tip o/BNDES_Setorial/201303_11.html

Chen, Z. (2003). Dominant retailers and the countervailing-power hypothesis. RAND Journal of Economics, 34(4), pp. 612-625.

Costa, F., \& Garcias, P. M. (2009). Concentração de mercado e desempenho das indústrias brasileiras de papel e celulose - recorrendo à modelagem de Fleuriet para analisar o paradigma ECD. RCO Revista de Contabilidade e Organizações, 3(6), pp. 143-163.

Demel, A. R. M. (2014). Reestruturação petrolífera na Argentina: estudo comparativo com o Brasil. Dissertação de mestrado, Universidade Federal do Rio de Janeiro, Rio de Janeiro, RJ, Brasil.

Denzin, N. K., \& Lincoln, Y. S. (1994). Handbook of qualitative research. London: Sage.

ENBAT. (n.d). Encontro Nacional de Produtores de Baterias Chumbo-Ácido. LACTEC. Recuperado em 10 outubro, 2013 de http://sistemas.lactec.org.br/xivenbat/home.htm

Fagundes, J., \& Pondé, J. L. (1998). Barreiras à Entrada e Defesa da Concorrência: Notas introdutórias, Cadernos de Estudo, Universidade Cândido Mendes.

Farina, E. M. M. Q. (1999). Competitividade e Coordenação de Sistemas Agroindustriais: um ensaio conceitual. Gestão e Produção, 6(3), pp. 147-161, dez.

Farina, E. M. M. Q. (2000). Oligopólio e política antitruste: desenvolvimentos recentes. FEA/USP, dez.

Farina, E. M. M. Q., Nunes, R., \& Monteiro, G. F. A. (2005). Supermarkets and their impacts on the agrifood system of Brazil: the competition among retailers. Agribusiness, 21(2), pp. 133-147.

FENIBAT. (2015). Feira Nacional e Internacional de Baterias de Chumbo. FENIBAT. Recuperado em 09 julho, 2015 de http://www.fenibat.com/index.php 
Fontana, A., \& Frey, J. H. (1994). Interviewing: the art of science. In: Denzin, N. K., \& Lincoln, Y. S. (orgs.). Handbook of qualitative research. London: Sage.

Freeman, F. M., \& Soete, L. (2008). A economia da inovação industrial. Campinas: Unicamp.

Goddard, J.; Tavakoli, M.; Wilson, J. (2005). Determinants of profitability in European manufacturing and services: evidence from a dynamic panel model. Applied Financial Ecnonomics, 17(18), pp. 1269-1282.

Hasenclever, L., \& Kupfer, R. (2013). Introdução. In: Kupfer, D., \& Hasenclever, L. (orgs.) Economia Industrial: fundamentos teóricos e práticas no Brasil. 2. ed., pp. xxi-xxix, Rio de Janeiro: Campus.

Hasenclever, L., \& Torres, R. (2013). O modelo Estrutura, Conduta e Desempenho e seus desdobramentos. In: Kupfer, D., \& Hasenclever, L. (orgs.) Economia Industrial: fundamentos teóricos e práticas no Brasil. 2. ed., pp. 41-51, Rio de Janeiro: Campus.

IAP. (n.d). Instituto Ambiental do Paraná. Missão e atribuições. Recuperado em 10 dezembro, 2013 de http://www.iap.pr.gov.br/modules/conteudo/conteu do.php?conteudo=348

IBAMA. (n.d). Instituto Brasileiro do Meio Ambiente e dos Recursos Naturais Renováveis. Controle de Resíduos. Recuperado em 10 dezembro, 2013 de https://www.ibama.gov.br/areas-tematicasqa/controle-de-residuos

IBGE. (2015). Instituto Brasileiro de Geografia e Estatística. CNAE 2.0. CNAE-Subclasses 2.2. Recuperado em 17 agosto, 2015 de https://cnae.ibge.gov.br/

IBGE/PIA-empresa. (2011). Instituto Brasileiro de Geografia e Estatística. Pesquisa Industrial Empresa 2011. Recuperado em 06 dezembro, 2013 de http://www.ibge.gov.br/home/estatistica/economia/i ndustria/pia/empresas/2011/defaultempresa.shtm

IBGE/PIA-produto. (2015). Instituto Brasileiro de Geografia e Estatística. Pesquisa Industrial Produto. Abr.

IBGE/RAIS. (2015). Instituto Brasileiro de Geografia e Estatística. Comitê de Estatísticas Sociais. Abr.

INMETRO. (2012). Instituto Nacional de Metrologia, Qualidade e Tecnologia. Portaria n 299 , de 14 de junho de 2012. Recuperado em 10 dezembro, 2013 de http://www.inmetro.gov.br/

Jacquemin, A. (2000). Theories of Industrial Organisation and Competition Policy: what are the links? European Comission, Working paper.

Jacquemin, A., \& Slade, M. E. C. (1996). Collusion and horizontal merger. In: Schmalensee, R. Willig, R. (Eds). Handbook of Industrial Organization. Amsterdam: Elsevier Science.

LACTEC. (n.d). Instituto de Tecnologia para Desenvolvimento. Recuperado em 10 dezembro, 2013 de http://www.lactec.org.br/pt/?page=instituto

Lipczynski, J., \& Wilson, J. (2004). The economics of business strategy. Prentice Hall - Financial Times.

Lipczynski, J., Wilson, J., \& Goddard, J. (2009). Industrial organization: competition, strategy, policy. 3. ed. Prentice Hall - Financial Times.

Losekann, L., \& Gutierrez, M. (2013). Diferenciação de Produtos. In: Kupfer, D., \& Hasenclever, L. (orgs.) Economia Industrial: fundamentos teóricos e práticas no Brasil. 2. ed., pp. 67-77, Rio de Janeiro: Campus.

Mason, E. S. (1939). Price and Production Policies of Large-Scale Enterprise. American

Economic Review, 29(1), pp. 61-74.

Mayring, P. (2000). Qualitative content analysis. FQS Forum: Qualitative Social Research, 1(2), art. 20, jun.

Mello, M. T. L. (2013). Defesa da Concorrência. In: Kupfer, D., \& Hasenclever, L. (orgs.) Economia Industrial: fundamentos teóricos e práticas no Brasil. 2. ed., pp. 285-298, Rio de Janeiro: Campus.

Morvan, Y. (1991). Fondements d'Économie Industrielle. Paris: Economica.

Neves, M. F., \& Conejero, M. A. (2010). Estratégias para a cana no Brasil. São Paulo: Atlas.

Porter, M. (1980). Competitive strategy: techniques for analyzing industries and

competitors. New York: The Free Press.

Porter, M. (1990). Vantagem Competitiva: criando e sustentando um desempenho superior. Rio de Janeiro: Campus.

Possas, M. L. (1987). Estruturas de mercado em oligopólio. 2. ed. São Paulo: Hucitec. 
Rocha, F. R. (2013). Coordenação Oligopolista. In: Kupfer, D., \& Hasenclever, L. (orgs.) Economia Industrial: fundamentos teóricos e práticas no Brasil. 2. ed., pp. 41-51, Rio de Janeiro: Campus.

Saes, M. S. M. (2009). Estratégias de diferenciação e apropriação de quase-renda na agricultura: a produção de pequena escala. São Paulo: Annablume, Fapesp.

Scherer, F. M, \& Ross, D. (1990). Industrial Market Structure and Economic Performance. 3. ed. Houghton Mifflin.

Schmalensee, R. (1988). Industrial Economics: an overview. The Economic Journal, 98, pp. 643-681.

Short, J. C., McKenny, A. F., Ketchen, D. J., Snow, C. C., \& Hult, G. T. M. (2015). An empirical examination of firm, industry, and temporal effects on corporate social performance. Business \& Society, pp. 1-35.
Silva, C. L. (2001). Competitividade e estratégia empresarial: um estudo de caso da indústria automobilística brasileira na década de 1990. Revista FAE, 4(1), pp. 35-48.

Teixeira, R., Lacerda, D. P., Hexsel, A., \& Castagno Junior, R. (2005). Fatores determinantes da competitividade na indústria de telecomunicações e repercussões para a estratégia. BASE - Revista de Administração e Contabilidade da Unisinos, 2(1), pp. $15-26$.

Triviños, A. N. S. (2010). Introdução à pesquisa em ciências sociais: a pesquisa qualitativa em educação. Atlas: São Paulo.

Setiawan, M., Emvalomatis, G., \& Lansink, A. O. (2013). Structure, conduct, and performance: evidence from the Indonesian food and beverages industry. Empirical Economics, 45(3), pp. 11491165. 